\title{
Metaphors of Weather in Canadian Short Prose
}

\begin{abstract}
In his recent book entitled Metaphor, Hungarian Lakoff-scholar Zoltán Kövecses translates the tenor-vehicle relationship into a linguistic Great Chain of Being (2002). The primary purpose of the paper is to examine how Canadian metaphors of weather fit into this framework. The first part of the paper presents some theoretical grounding, proceeding from the overt-covert and direct-indirect relationship of tenor and vehicle to Lakoff's cognitive concept of metaphor (1980, 1993). Based on this concept, the linguistic Great Chain of Weather Metaphors is created. The second part of the paper makes an attempt at examining the most typical source and target domains of weather, and, based on a pilot sample, it also looks into conceptual weather metaphors built by mapping at each level of the Great Chain of Weather Metaphors. Furthermore, the analysis tackles the question of conventionality as well as the establishment of a certain hierarchy among the different Great Chain levels through the employment of Ricoeur's Platonic ladder theory (1987) and Lakoff's principle of unidirectionality (1990). This section of the paper is followed by an in-depth analysis focusing on objectto-weather and weather-to-object correspondences.
\end{abstract}

Key words

Cognitive concept of metaphor; mapping; unidirectionality; metaphors of weather; Canadian short stories

\section{Introduction}

My earlier research results (Nagy 2009) clearly indicate that there is much concreteness in the Canadian weather idiom, where Margaret Atwood's premise "If it is cold, Canadians say so" (1981: 35) and George Woodcock's comment on the "concrete and highly visual nature" (1976: 2) of Canadian writing certainly ap- 
ply. Yet, the current paper will be devoted to a form of abstraction. Why then the attention paid to something that may prove rather marginal in the given context? Noted representatives of deconstruction and postcolonialism such as Derrida (1986), Hillis Miller (1986) or Said (1983) have long called the attention to the possible gains that can result from studying the margins. In this spirit, the present paper may be viewed as a quest for the potential worth of looking into Canadian metaphors of weather along the cognitive linguistic lines represented by Hungarian scholar, Zoltán Kövecses.

It is the relatively close connection of Canadian writing with reality that entitles us to use the cognitive approach when dealing with the metaphor. According to this, "our experiences with the physical world serve as a natural and logical foundation for the comprehension of more abstract topics" (Kövecses 2002: 6). More generally, "the natural and physical environment shapes a language, primarily its vocabulary, in an obvious way; consequently, it will shape the metaphors, as well" (Kövecses 2002: 187).

Both the terms metaphor and weather will be used in their widest possible sense in the present paper, the former as displacement, "a category switch between weather and a different entity in order to vividify" (Kövecses 2002: 9), and the latter to include borderline cases such as the sky as the stage for the performance of the weather, the moon to indicate a clear night sky, or dust as an index of drought.

\section{From overt-covert and direct-indirect to the cognitive concept of metaphor}

In my research on weather images, two scales have been set up for measuring abstraction in the research sample, that is, the New Oxford Book of Canadian Short Stories edited by two acclaimed Canadian literary critics, Margaret Atwood and Robert Weaver. One scale moves along the axis of overtness, the other examines directness.

I have termed a reference overt if the vehicle refers to an actual quality of the tenor. The terms tenor and vehicle are used in the I. A. Richardsean sense, the former denoting "the purport or general drift of thought regarding the subject of the metaphor," the latter signifying "the image which embodies the tenor" (Cuddon 1999: 904). In the sentence "I always thought that snow was white" (Marshall 1995: 35) the word white describes a quality that would also normally belong to snow. However, this relationship does not hold in the case of a covert reference. Consider "her voice has gone white" (Findley 1995: 115), for example. Here white is a reference to the whiteness of the snow surrounding the female protagonist of Timothy Findley's 'The Duel in Cluny Park' whereas it is human voice this whiteness is attributed to. Again, if you take the phrase "the almost instantly blinding glare of the snow" (Marshall 1995: 36) the word glare, apart from the meaning strong, unpleasant, dazzling light can be associated with a person's angry way of looking, so weather allows for the admission of human qualities here. 
It follows from the previously said that images with the potential of projecting human characteristics onto weather or weather characteristics onto humans belong to the covert category. Out of the total of 1032 weather images listed in an earlier research (Nagy 2009), it appears that roughly a mere third belong to the covert category.

Now let us consider the question of direct and indirect images. An image is regarded as direct in my interpretation if it is mentioned in a given text. "The fields were dead with snow" (Reaney 1995: 97) contains a direct weather image because the word snow is mentioned in it. An indirect image shows only the consequences of a given weather phenomenon, the phenomenon itself is not mentioned. In Clark Blaise's story 'A Class of New Canadians' we view slithering taxis and slushy curbs roaming the streets of Montreal (1995: 277). Even though snow itself is not mentioned in either case, the words slithering and slushy imply that there is snow on the road on which taxis are sliding, and this snow is partly melted to form slush. Again, based on the above-mentioned total weather image list (Nagy 2009), we find that there is a threefold abundance of direct images as compared to indirect ones, that is, only about $25 \%$ qualify as an indirect image. (Note that an image can be covert yet direct, that is, the two categories are not congruent. The image "fields dead with snow" (Alistair MacLeod 1995: 227) is covert as it involves personification, yet, the word snow is present in it therefore it is direct.)

One can easily see that the above definition of the covert category gives us a metaphorical mapping since cognitive linguistics defines metaphor as "understanding one conceptual domain in terms of another" (Kövecses 2002: 4) wherein the "individual instances of the mapping from the one domain (source) to the other (target) are called linguistic metaphors or metaphorical linguistic expressions" (Kövecses 2002: 25).

As far as the above indirect category is concerned, it seems to coincide with what Kövecses interprets as metonymy: "a cognitive process in which one conceptual entity provides mental access to another conceptual entity within the same domain" (2002: 145). This definition includes more than the classical part-forwhole associations, and introduces the concept of the idealized cognitive model (ICM), which is the domain that links the vehicle and the target, and which enables us to interpret examples such as slithering taxis within metonymy.

Last, it was noted that covert does not necessarily mean indirect. When Kövecses speaks of the relationship between metaphor and metonymy, he mentions that "particular linguistic expressions are not always clearly metaphors or metonymies. Often, what we find is that an expression is both" (2002: 159). Hence the occasional overlap between overtness and directness: a metaphoric and a metonymic index, which, however, are not congruent. 


\section{The Great Chain of Weather Metaphors}

In the following, we will concentrate on the metaphoric rather than the metonymic. ${ }^{1}$ To further develop Kövecses's idea of creating a linguistic Great Chain of Being (2002), it is possible to arrange linguistic metaphors of weather into a linguistic Great Chain of Weather Metaphors. (Figures 1 and 2). ${ }^{2}$ In congruence with the remarks in the introduction, and as the quantitative markers along the overt-overt axis also indicated in the previous point, the 301 Great Chain of Weather Metaphors amount to about $29 \%$ of the weather image total of the New Oxford Book of Canadian Short Stories sample.

$\mathbf{G}<\mathbf{w}$ (God-to-weather correspondences):

"[Kezia] humming a psalm tune ... to the snow" (Raddall 1995: 27)

God is projected onto the snow because a psalm is normally sung to God and not to the snow.

A psalm is sung to God. $\rightarrow$ A psalm is sung to the snow.

$\mathbf{p}<\mathbf{w}$ (person-to-weather correspondences):

"the air died" (Wilson 1995: 2)

A person dies. $\rightarrow$ The air dies (windstill).

$\mathbf{a}<\mathbf{w}$ (animal-to-weather correspondences):

"frost that was set like a weasel upon killing in the night" (Kinsella 1995: 203)

weasel set upon killing $\rightarrow$ frost set upon killing

$\mathbf{p l}<\mathbf{w}$ (plant-to-weather correspondences):

"you were sowing rain" (Adderson 1995: 439)

seeds $\rightarrow$ rain

$\mathbf{0}<\mathbf{w}$ (object-to-weather correspondences):

"a white dusting" (Cohen 1995: 303)

dusting in white $\rightarrow$ snow

abstr $<\mathbf{w}$ (abstract-notion-to-weather correspondences):

"a sun that first dazzled then inflamed the eyes" (Marshall 1995: 35)

Disease can dazzle and inflame the eyes. $\rightarrow$ Weather inflames the eyes.

\section{Mixed}

e.g.: $\mathrm{a}<\mathrm{w}+\mathrm{o}$

"rooster tails of snow and exhaust" (Flood 1995: 290)

shape of rooster's tail $\rightarrow$ shape of snow + exhaust

Figure 1. The Great Chain of Weather Metaphors I $-x<w$ correspondences 


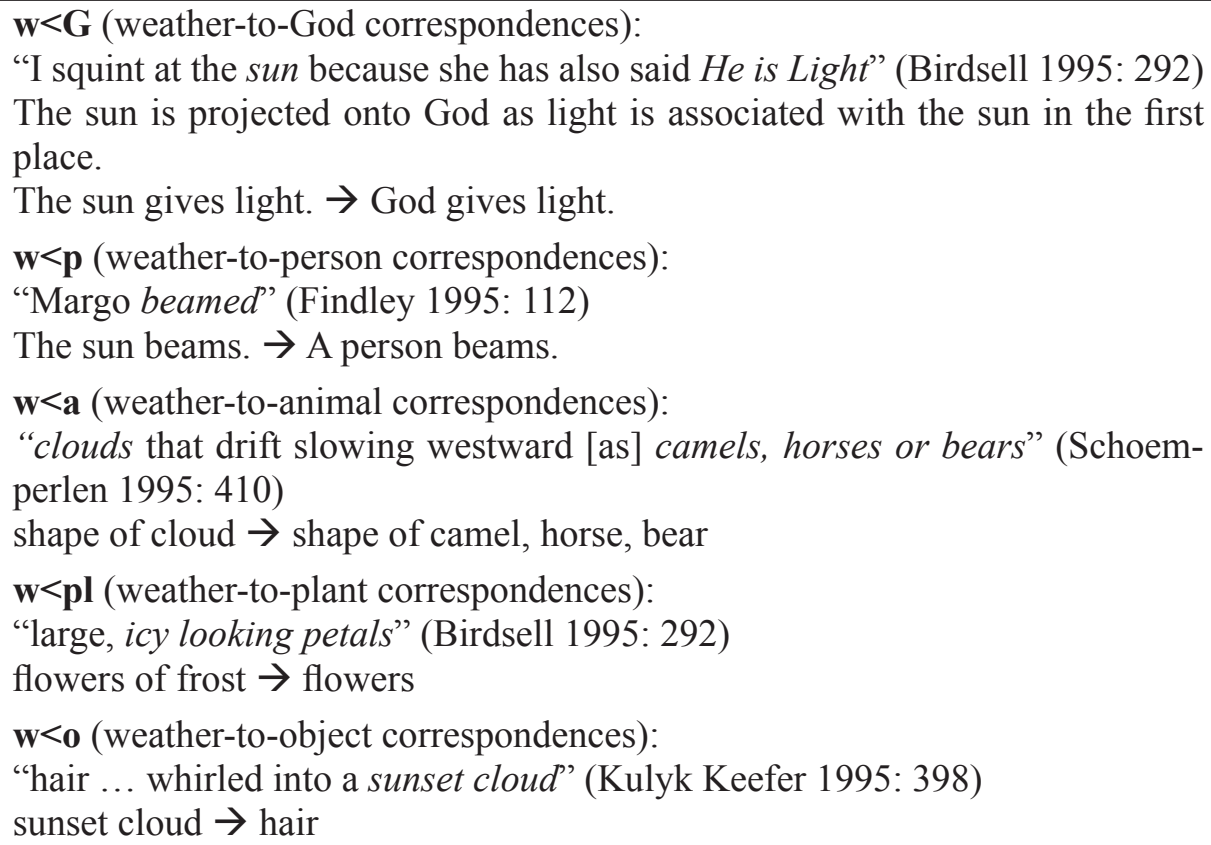

$\mathbf{w}<$ abstr (weather-to-abstract-notion correspondences): "It was the last day before the thaw when the tension broke, like northern lights exploding in the frozen air" (Huggan 1995: 309)

Northern lights explode. $\rightarrow$ Tension explodes.

\section{Mixed}

e.g.: $\mathrm{a}+\mathrm{w}<\mathrm{o}$

"marbles, baseballs, tennis balls and ball bearings all accumulate in a corner like a herd of cattle clustered with their backs to the storm" (Kinsella 1995: 199)

arrangement of cattle with their backs to the storm $\rightarrow$ arrangement of balls

Figure 2. The Great Chain of Weather Metaphors II $-w<x$ correspondences

The difference between the x-to-weather (Figure 1) and the weather-to-x (Figure 2) transformations must be noted and explained. In the first type, Great Chain characters are projected onto weather, whereas in the second type, weather is projected onto Great Chain characters.

The chain is topped by the God-to-weather $(G<w)$ and weather-to-God $(w<G)$ transformations, respectively. Human, animal, plant and object replace God as the Great Chain is descended. At the bottom of the two charts, two extra types of correspondence are marked: abstract-notion-to-weather (abstr $<w, w<a b s t r)$, and the mixed type category containing complex cases where weather forms some part of the correspondence (e.g. $a<w+o, o<a+w$, etc.), that is, the Great Chain 
categories are combined into the $x(/+c)<w(+d)$ and $w(/+c)<x(+d)$ patterns, where $\mathrm{x}, \mathrm{c}$ and $\mathrm{d}$ denote the given Great Chain categories (God, person, animal, plant, abstract notion) and $\mathrm{w}$ denotes weather. As this implies, the mentioned $a<w+o$ and the $a+w<o$ patterns (Figures 1 and 2) are just one realization of potential combinations in the respective categories.

The abstract-notion-to-weather $(a b s t r<w)$ and the weather-to-abstract-notion $(w<a b s t r)$ categories have a special subcategory: weather-to-weather transformations (Figure 3). Their importance will be revealed in the next point.

$\mathbf{w}<\mathbf{w}$ (weather-to-weather correspondences):

Northern lights are pictured as "lightning that never descended to earth" (Laurence 1995: 85).

Some lightning does not descend to earth. $\rightarrow$ Aurora borealis does not descend to earth.

Figure 3. Weather-to-weather correspondences

\section{Frequency}

One may be intrigued to ascertain how numerous the different Great chain levels are, and whether there is any pattern that persists. Figure 4 contains the distribution of linguistic weather metaphors by each Great Chain level, both for x-toweather $(x<w)$ and for weather-to-x $(w<x)$ transformations.

\begin{tabular}{|lrr|}
\hline Level of Great Chain (x) & $\mathbf{x}<\mathbf{w}$ & $\mathbf{w}<\mathbf{x}$ \\
$\mathbf{G}$ & $1.3 \%(3)$ & $1.6 \%(3)$ \\
$\mathbf{p}$ & $19.6 \%(18)$ & $16.2 \%(17)$ \\
$\mathbf{a}$ & $2.6 \%(7)$ & $0.3 \%(1)$ \\
$\mathbf{p l}$ & $0.6 \%(2)$ & $0.3 \%(1)$ \\
$\mathbf{0}$ & $14.9 \%(15)$ & $11.9 \%(13)$ \\
$\mathbf{w}$ & & $4 \%(10)$ \\
abstr & $0.3 \%(1)$ & $4.3 \%(8)$ \\
mixed & $16.6 \%(13)$ & $2 \%(4)$ \\
altogether & $58 \%$ & $38 \%$ \\
\hline
\end{tabular}

Figure 4. Distribution of weather metaphors by Great Chain Levels

Undoubtedly, x-to-weather mappings are more numerous in total than weatherto-x ones in the sample. Once the chain is examined level by level, the lead of the first type of correspondence persists, apart from the God-to-weather and the abstract-notion-to-weather levels. Concerning the former, the sample may be 
too small to be reliable, or, Nature and God may be regarded as synonymous, a Western World Romantic heritage (Buell 1986), which can also account for the discrepancy. As for abstract-notion-to-weather type of correspondences, weather may entail abstract notions, which can alter the actual mapping pattern of correspondences. In metaphor, "thinking about the abstract concept is facilitated by a more concrete concept" (Kövecses 2002: 4). This implies that if the given weather phenomenon is considered to be more abstract than the abstract part of the correspondence, tenor and vehicle may switch position hence the relatively large number in the $w<$ abstract category.

Second, the most frequent levels in the Great Chain of linguistic weather metaphors are the person-to-weather, weather-to-person, and the object-to-weather, weather-to-object type of correspondences. This finding coincides with Western World traditions attributing great literary importance to personification (Cuddon 1999), and the importance of objects as manifestations of and ways to access the abstract (Ricoeur 1987).

The figures in brackets (Figure 4) inform about how many different weather images combine into linguistic metaphors at the given level of the Great Chain. In this respect, the variety of combinations appears to be roughly in proportion to the number of metaphors in the given category, ${ }^{3}$ which index points towards a certain degree of variety in expression.

Three weather images seem to dominate the $x<w$ pattern: sun, snow and wind. Preference for the universal 'sun' is strong. To furnish a possible explanation, universal images climb the symbolic ladder faster (Ricoeur 1987).

In the case of the $w<x$ correspondences, temperature (heat) is the most dominant, followed by sun, and clouds, all being universal images. It is important to note though that the next three ranks are taken by the stereotypically Canadian frost, temperature (cold) and snow. What is common in all the top six image groups for this category is that they are direct or potential indirect indications of temperature, thus forming part of the universal emotion-to-temperature mapping (Kövecses 2002).

As for the mixed categories of Great Chain of Weather Metaphors (see Figures 1 and 2), the universal and metaphorically versatile wind forms part of the highest number of such complex correspondences, both suitable to express motion and change (source) and allowing for the metaphorical expression of emotions (target), yet rarely occurring alone as it is mostly present through its effect on its environment.

Once temporal markers are also taken into consideration, it is discernible that the dominance of universal images has become a trend in the last two decades, largely due to the recent proliferation of ethnic short story writers on the palette of Canadian literature (Nagy 2009). ${ }^{4}$ 


\section{The Platonic ladder of weather metaphors}

Both Ricoeur's Platonic ladder concept (1987) $)^{5}$ and Lakoff's principle of unidirectionality $(1990)^{6}$ suggest that a certain hierarchy may apply to the two types of the Great Chain as displayed in Figures 1 and 2, respectively. Furthermore, Kövecses comments on the person-to-animal and animal-to-person correspondences as follows: "animals were personified first, and then the human-based animal characteristics were used to understand human behaviour" (2002: 118). If we translate this observation into our weather project, it implies that the person-toweather type correspondence (e.g. the wind whimpers) is inferior to the weatherto-person type one (e.g. He stormed out) in that the latter signifies an earlier step in the metaphorical process, and, consequently, it is more common. And, to generalize further, this may suggest the superiority of the $w<x$ type of linguistic metaphors over the $x<w$ type ones as far as abstraction is concerned. ${ }^{7}$

Speaking of abstraction, complexity is another factor here, which concerns the $x(/+c)<w(+d)$ and $w(/+c)<x(+d)$ patterns as explained in point three. To exemplify these, let us consider the expression "winter buried you" (Marshall 1995: 36) The word bury can refer to a human or animal agent, therefore it is classified as $p / a<w$. The expression "new lands where the weather is as stupid as the trees" (Metcalf 1995: 234) reveals another mixed subtype: here the attribute stupid links weather and the trees to enter the mapping jointly to produce the formula $x<w+p l$. What this instant structural analysis suggests is that mixed types belong to a higher degree of abstractional complexity.

Figure 5 displays the hierarchy thus derived along with the respective figures of frequency, which show a steady decrease, implying that (1) weather as a source realises a higher degree of abstraction than weather as a target, and (2) the higher the complexity the less numerous the given group of weather metaphors.

$$
\begin{aligned}
& \mathrm{x}<\mathrm{W}(175) \\
& \mathrm{w}<\mathrm{x}(116) \\
& \mathrm{x}(/+\mathrm{c})<\mathrm{W}(+\mathrm{d})(50) \\
& \mathrm{w}(/+\mathrm{c})<\mathrm{x}(+\mathrm{d})(6)
\end{aligned}
$$

ABSTRACTION

Figure 5. Assumed hierarchy of correspondence types based on data gained from the examined sample

\section{Analysis}

Next, let us look into the actual linguistic metaphorical expressions which make the various levels of our linguistic Great Chain of Weather and examine how Canadian they are. The cognitive view of metaphor "maintains that - in addition to objective, pre-existing similarity [i.e. the traditional view of metaphor] - metaphors are based on a variety of human experience, various kinds of non-objective 
similarity, biological and cultural roots shared by the two concepts and possibly others" (Kövecses 2002: 69). Kövecses holds the following on cultural variation in metaphor:

Two large categories [...] bring about cultural variation in metaphor (and metonymy): 1. broader cultural context, 2 . natural and physical environment. [...] Even those metaphors that are universal at the generic level may be very different at the level of actual realization depending on the given culture $[\ldots$ let alone] culture specific concepts $[\ldots$ ] Given a certain kind of habitat, speakers living there will be attuned (mostly unconsciously) to things and phenomena that are characteristic of that habitat; and they will make use of these things and phenomena for the metaphorical comprehension and creation of their conceptual universe (2002: 186-187).

What this suggests for the sample is that the two influential factors determining originality will be Western World image conventions, in which context Canadian short fiction is certainly embedded (Kröller 2004), and the effect of the physical environment on image formation. The former is in support of conventionality, while the latter may be responsible for generating the more original realizations of our Great Chain of Weather Metaphors.

For the lack of space we have selected only one great chain level for detailed discussion: that of objects, which includes object-to-weather and weather-to-object correspondences, and where object is defined in a broader sense, as a tangible or visible entity, allowing words like night, bruise or car exhaust to enter this category but excluding freedom and similar items.

\section{$6.10<w$ correspondences}

The third most frequent in the $x<w$ category, object-to-weather correspondences involve fifteen different weather images, which practically means that they are present in almost every image category. Like a piece of clothing, clouds may be tattered (Ross 1995: 26) just as they may be perceived as "blue-black bruises in a night sky" (Schoemperlen 1995: 410) or have the curdly (Kinsella 1995: 199) quality of milk gone off in the case of the layered and flattened dusk cumuli, all three metaphors alluding to the violent atmospheric hands that form clouds. Thunder and gunfire are brought together in a conventional parallel in Caroline Adderson's 'The Chmarnyk': "thunder discharged, a firearm, reverberating" (440). A dust storm is like a pill, farmers are "to swallow it" (Ross 1995: 30). The objects dust plug (Adderson: 439) in the corner of the eye, dust reel (Ross 1995: 26) and the empty desert (Wilson 1995: 5) characterize drought - all unpleasant associations of the all-pervasive cover that fills everything. Equally unpleasant, a "spear of icicle" (Adderson 1995: 437) and frost making grass crisp as a bleaching agent (Kinsella 1995: 437) become potential weapons for Nature to kill. Conventionally, cold visualizes as "breath hang[ing] visible" (Raddall 1995: 
19) whereas heat may be associated with the womb: "At the house the heat was manageable. It suggested comfort, security; it was like the heat of the womb" (Bissoondath 1995: 432).

Celestial bodies often realize as a piece of ornamentation in the sky: a picture on the wall, "the moon hangs low" (Flood 1995: 286), "there could have been $a$ hand holding the sun" (Bowering 1995: 196). A heavy object, the sun can "sink behind the mountains" (Bissoondath 1995: 435), and it is often perceived as a round, circular object: a "lamp lit," a "disc with a silver rim" (Valgardson 1995: 271), or, more originally, a "wizened orange" (Ross 1995: 26) reflecting the post-modern whimper in which the dust storm of 'The Lamp at Noon' ends. Like an overripe tomato, the sun may "burst and stain the sky" (Thomas 1995: 221) at sunset. Quite conventionally, the sky at sunset is likened to fire burning in Caroline Adderson's 'The Chmarnyk': "every evening the sky flare[s]" (1995: 437), and the protagonist's face in Sandra Birdsell's 'Flowers for Weddings and Funerals' "reflect[s] the fired sky" (1995: 265)

Rain makes an appearance both in conventional and original metaphors: it forms "a dark curtain [which is] drawn across the Palliser Triangle" (Adderson 1995: 440), it is the heavenly spittle of "saliva on the dusty glass" (Adderson 1995: 438), whereas raindrops are represented as "beads of a rosary" (Adderson 1995: 438) implying a prayed-for blessing, a cure for the parched land. An unconventional realization is rain seen as "black geyser sky" (Adderson 1995: 440) with the world turned upside down as geysers normally gush forth from the ground, involving physical forces. The most numerous among weather images entering into the object-to-weather mapping, another form of precipitation, snow reveals two dominant groups of its perception: a thin or a thick covering layer. In Matt Cohen, it is presented as "a white dusting" (1995: 303), in Margaret Laurence, it "sift [s] onto the porch" (1995: 86), in Thomas H. Raddall, it is "like flung salt" (1995: 18) and a "sediment from the storm" (1995: 19), and, in Margaret Gibson, it forms a "frozen sheet" (1995: 339), all of which images suggest a thin layer. When snow is perceived as a thick layer, it makes Raddall's "carpets of ermine" (1995: 14), Gibson's deep blanket (1995: 339), or Laurence's "huge and white desert" (1995: 85). An original, sinister parallel links snow to steel, which is present in two stories: in Margaret Gibson, "steel snowflakes fall" (1995: 338) and, in Joyce Marshall, snow is "blue and treacherous as steel" (1995: 39). Steel also brings together cold wind with sword as in Margaret Laurence's expression "the steel cutting edge of the wind" (1995: 78) while James Reaney compares cold wind to a river based on the roaring sound that results: "a cold strong river of wind roared" (1995: 100), both conventional metaphors building around unpleasant attributes.

In the above rich collection of object-to-weather correspondences quite a few examples occur which relate to forces causing motion and change (Kövecses 2002) such as the violent hands forming clouds, the bursting sun at sunset, the cloudburst of black geyser sky, snow as flung salt, or the sharp steel sword and roaring river of wind. 


\section{$6.2 w<0$ correspondences}

Thirteen different weather images enter the chain at the level of weather-to-object correspondences. One frequent and typically conventional pattern is to combine the time of the day with a weather phenomenon in this class: the expression sunny day would infer that it is the measure of time that is sunny but in fact it describes the weather. Similarly, consider Caroline Adderson's example "the day dry and searing" (1995: 440) or Linda Svendsen's “sultry Saturday morning" (Svendsen 1995: 420). The sun is particularly likely to surface in such contexts as can be exemplified with the expressions "sunny afternoon" (Clarke 1995: 167, also Cohen 1995: 301), Alice Munro's “unsettling bright morning" (1995: 136) or Ethel Wilson's "bright, hot, loud afternoon" (1995: 6). It is worth mentioning that most of the enumerated instances are also spiced with emotional overtones.

The conventional cloud-dress parallel surfaces in Austin G. Clarke's 'Griff!', whose protagonist clothes his wife in the "cloud of virginity and sanctity" (1995: 158). More originally, Janice Kulyk Keefer's "circumambient chemical cloud" (1995: 398) of a hairdressing salon characterizes hair-spray. In addition, hair creations are also referred to in terms of clouds in the same story: "hair like cotton candy whirled into a sunset cloud around the cone" (1995: 398). In the same context, "snowy mousses" (1995: 402) are applied on customers. The other weatherto-object correspondence for snow links it with the moon, their whiteness being the common denominator: "the moon is full, snow white" (Schoemperlen 1995: 410).

Originally, Carol Shields's expression, "drizzled syrup on pancakes" (Shields 1995: 210) is associated with the drizzle of clouds, whereas the weekend is compared to the much wished for "raindrops on a farmer's dry season head" (Clarke 1995: 163) playing on the rain-as-cure convention. A related weather phenomenon, thunder is projected onto objects as diverse as a chair (Margaret Laurence), a weapon (Rudy Wiebe) or water (Joyce Marshall), the similarity being based on sound. For example, Grandfather MacLeod's chair is "thudding like retreating thunder" (Laurence 1995: 84). Also, thunder may be projected onto a document, as in "all the thunder of "A Proclamation"" (Wiebe 1995: 188) where it refers either to the power or the reception of the document in accordance with the conventional connection between forces and politics (Kövecses 2002).

The most numerous group within the $w<O$ category is that of temperaturerelated correspondences. Cold or cool are associated with unpleasant experiences, and they frequently come with an emotional overtone, as Linda Svendsen's “crisp, windy night" (1995: 421), or Diane Schoemperlen's "cool grey day" (1995: 406). Associations with heat appear to be equally negative, such as Margaret Atwood's “hot and stifling" evening (1995: 247), or Margaret Gibson's morning, "heavy and warm" (1995: 343). Heat usually triggers a muggy atmosphere in these stories, not void of emotional overtones. As the enumerated examples also suggest, heat and cold make suitable conventional sources to connect to the emotive sphere. 


\section{Conclusion}

To sum up the findings of the current paper, based on Lakoff's's cognitive linguistic concepts $(1980,1990,1993)$ and Kövecses's linguistic Great Chain of Being (2002), the Great Chain of Weather Metaphors was constructed, the most numerous levels of which are the ones with mappings involving person and object, presumably due to the distinguished role these take in the process of metaphorization. The universal images of the sun and the heat lead the $x<w$ and the $w<x$ image group in frequency. The most frequent complex metaphorical component is the wind, suiting the role of both source and target.

A certain hierarchy seems to prevail among the various metaphorical linguistic expressions making up the Great Chain of Weather Metaphors, which seems to be determined by two factors: complexity and whether weather functions as a target or a source domain.

As far as the individual realizations are concerned, force and violence-related metaphorical linguistic expressions dominate the $x<w$ pattern with weather as target, while the $w<x$ pattern is dominated by weather being an emotive source.

As for originality, the examples in the analysis illustrate that there are not many repetitions in the individual linguistic metaphors. Another finding in support of variety is the number of different weather images entering into mapping at each level of the Great Chain. In the case of $x<w$ correspondences, only few fixed phrases or idioms occurred whereas in the case of the $w<x$ type, their number was considerably higher. As far as systematic mappings are concerned, these seem to converge to Western World patterns, so we cannot speak of originality in this sense, especially in the case of the $x<w$ type. Conventional knowledge, defined as "shared knowledge that people in a given culture have concerning a given conceptual domain" (Kövecses 2002: 208) influences metaphor formation. One can thus perceive the process of Canadian weather metaphorization as a battle between Western World tradition (cultural factor) and physical reality (environmental factor). Based on the findings of the survey, it seems that cultural patterns (i.e. convergence to Western World conventions) are the most emphatic element in forming the metaphors of Canadian short prose.

\section{Notes}

1 One may desire to see the extent of overlap between the metaphoric and the metonymic indices. In this respect, my hypothesis based on the examined sample is that where one is strong, the other is not - thus we experience a certain one-dimensional abstraction, which reinforces the concrete nature of Canadian short story writing, at least weather-wise. It must be noted that all formulae in the article are the author's invention.

A certain discrepancy may occur in values within the statistical error margin. Also, the $x<w$ and the $w<x$ classes may operate with a different proportional factor. Hence 13 metaphors combine into 50 examples in the $x<w$ (mixed) class whereas they generate only 36 examples in the $w<o$ group of metaphors. 
the nationalism of the 1970s in search of truly Canadian characteristics, weather images stereotypical of Canadian climate, such as snow or frost, prevailed in this period (Nagy 2009). In Ricoeur's views, things must climb the Platonic ladder before they become abstract - each abstract notion roots in the concrete (1987). According to Lakoff, "the metaphorical process typically goes from the more concrete to the more abstract" (1990: 56).

\section{References}

Adderson, Caroline (1995) 'The Chmarnyk'. In: Atwood, Margaret and Robert Weaver (eds.) The New Oxford Book of Canadian Short Stories. Oxford: Oxford University Press, 436-441.

Atwood, Margaret (1995) 'True Trash'. In: Atwood, Margaret and Robert Weaver (eds.) The New Oxford Book of Canadian Short Stories. Oxford: Oxford University Press, 247-266.

Atwood, Margaret (1981) Survival. Toronto: Anansi Press.

Birdsell, Sandra (1995) 'Flowers for Weddings and Funerals'. In: Atwood, Margaret and Robert Weaver (eds.) The New Oxford Book of Canadian Short Stories. Oxford: Oxford University Press, 292-296.

Bissoondath, Neil (1995) 'Digging Up the Mountains'. In: Atwood, Margaret and Robert Weaver (eds.) The New Oxford Book of Canadian Short Stories. Oxford: Oxford University Press, 423 435.

Blaise, Clark (1995) 'A Class of New Canadians'. In: Atwood, Margaret and Robert Weaver (eds.) The New Oxford Book of Canadian Short Stories. Oxford: Oxford University Press, 277-283.

Bowering, George (1995) 'The Hayfield'. In: Atwood, Margaret and Robert Weaver (eds.) The New Oxford Book of Canadian Short Stories. Oxford: Oxford University Press, 193-198.

Buell, Lawrence (1986) New England Literary Culture from Revolution Through Renaissance. Cambridge: Cambridge University Press.

Clarke, Austin G (1995) 'Griff!'. In: Atwood, Margaret and Robert Weaver (eds.) The New Oxford Book of Canadian Short Stories. Oxford: Oxford University Press, 156-170.

Cohen, Matt (1995) 'Trotsky's First Confessions'. In: Atwood, Margaret and Robert Weaver (eds.) The New Oxford Book of Canadian Short Stories. Oxford: Oxford University Press, 297-306.

Cuddon, J. A. (1999) The Penguin Dictionary of Literary Terms and Literary Theory. London: Penguin Books.

Derrida, Jacques (1986) 'Structure, Sign and Play in the Discourse of the Human Sciences'. In: Adams, Hazard and Leroy Searle (eds.) Critical Theory Since 1965. Tallahassee: University Presses of Florida. 83-94

Findley, Timothy (1995) 'The Dual in Cluny Park'. In: Atwood, Margaret and Robert Weaver (eds.) The New Oxford Book of Canadian Short Stories. Oxford: Oxford University Press, 110-130.

Flood, Cynthia (1995) 'The Meaning of the Marriage'. In: Atwood, Margaret and Robert Weaver (eds.) The New Oxford Book of Canadian Short Stories. Oxford: Oxford University Press, 284291.

Hillis Miller J. (1986) 'The Critic as a Host'. In: Adams, Hazard and Leroy Searle (eds.) Critical Theory Since 1965. Tallahassee: University Presses of Florida. 452-468.

Huggan, Isabel (1995) 'Celia Behind Me'. In: Atwood, Margaret and Robert Weaver (eds.) The New Oxford Book of Canadian Short Stories. Oxford: Oxford University Press, 307-312.

Kinsella, W. P. (1995) 'Shoeless Joe Jackson Comes to Iowa'. In: Atwood, Margaret and Robert Weaver (eds.) The New Oxford Book of Canadian Short Stories. Oxford: Oxford University Press, 199-209.

Kövecses, Zoltán (2002) Metaphor. Oxford: Oxford University Press. 
Kröller, Eva-Marie (2004) The Cambridge Companion to Canadian Literature. Cambridge: Cambridge University Press.

Kulyk Keefer, Janice (1995) 'Transfigurations'. In: Atwood, Margaret and Robert Weaver (eds.) The New Oxford Book of Canadian Short Stories. Oxford: Oxford University Press, 398-403.

Lakoff, George (1993) 'The Contemporary Metaphor'. In: Ortony, Andrew (ed.) Metaphor and Thought. Cambridge: Cambridge University Press. 202-251.

Lakoff, George and Mark Johnson (1980) Metaphors We Live By. Chicago: The University of Chicago Press.

Lakoff, George (1990) 'The Invariance Hypothesis: Is Abstract Reason Based on Image Schemas?'. In: Cognitive Linguistics 1, 39-74.

Laurence, Margaret (1995) 'The Mask of the Bear'. In: Atwood, Margaret and Robert Weaver (eds.) The New Oxford Book of Canadian Short Stories. Oxford: Oxford University Press, 76-91.

MacLeod, Alistair (1995) 'As Birds Bring Forth the Sun'. In: Atwood, Margaret and Robert Weaver (eds.) The New Oxford Book of Canadian Short Stories. Oxford: Oxford University Press, 224-229.

Marshall, Joyce (1995) 'The Old Woman'. In: Atwood, Margaret and Robert Weaver (eds.) The New Oxford Book of Canadian Short Stories. Oxford: Oxford University Press, 34-43.

Metcalf, John (1995) 'The Years in Exile'. In: Atwood, Margaret and Robert Weaver (eds.) The New Oxford Book of Canadian Short Stories. Oxford: Oxford University Press, 233-246.

Munro, Alice (1995) 'The Jack Randa Hotel'. In: Atwood, Margaret and Robert Weaver (eds.) The New Oxford Book of Canadian Short Stories. Oxford: Oxford University Press, 131-148.

Nagy, Judit (2009) But a Few Acres of Snow? - Weather Images in Canadian Short Prose 19452000. Budapest: ELTE.

Raddall, Thomas H. (1995) 'The Wedding Gift'. In: Atwood, Margaret and Robert Weaver (eds.) The New Oxford Book of Canadian Short Stories. Oxford: Oxford University Press, 14-25.

Reaney, James (1995) 'The Bully'. In: Atwood, Margaret and Robert Weaver (eds.) The New Oxford Book of Canadian Short Stories. Oxford: Oxford University Press, 92-100.

Ricoeur, Paul (1987) 'A nyelvről, a szimbólumról és az interpretációról'. In: Fabiny, Tibor (ed.) Ikonológia és müértelmezés. Szeged: University of Szeged Press. 179-218.

Ross, Sinclair (1995) 'The Lamp at Noon'. In: Atwood, Margaret and Robert Weaver (eds.) The New Oxford Book of Canadian Short Stories. Oxford: Oxford University Press, 26-33.

Saïd, Edward W. (1983) 'Introduction to Secular Criticism'. In: The World, the Text and the Critic. Cambridge, Massachusetts: Harvard University Press. 1-30.

Schoemperlen, Diane (1995) 'Red Plaid Shirt'. In: Atwood, Margaret and Robert Weaver (eds.) The New Oxford Book of Canadian Short Stories. Oxford: Oxford University Press, 404-412.

Shields, Carol (1995) 'Milk Bread Beer Ice'. In: Atwood, Margaret and Robert Weaver (eds.) The New Oxford Book of Canadian Short Stories. Oxford: Oxford University Press, 210-217.

Svendsen, Linda (1995) 'White Shoulders'. In: Atwood, Margaret and Robert Weaver (eds.) The New Oxford Book of Canadian Short Stories. Oxford: Oxford University Press, 413-422.

Thomas, Audrey (1995) 'Bear Country'. In: Atwood, Margaret and Robert Weaver (eds.) The New Oxford Book of Canadian Short Stories. Oxford: Oxford University Press, 218-223.

Valgardson, W. D. (1995) 'God is Not a Fish Inspector'. In: Atwood, Margaret and Robert Weaver (eds.) The New Oxford Book of Canadian Short Stories. Oxford: Oxford University Press, 267276.

Wiebe, Rudy (1995) 'Where Is the Voice Coming From?'. In: Atwood, Margaret and Robert Weaver (eds.) The New Oxford Book of Canadian Short Stories. Oxford: Oxford University Press, $185-192$.

Wilson, Ethel (1995) 'Haply the Soul of My Grandmother'. In: Atwood, Margaret and Robert Weaver (eds.) The New Oxford Book of Canadian Short Stories. Oxford: Oxford University Press, $1-8$.

Woodcock, George (1976) 'Places of Past and Pride'. In: Canadian Literature. Vol. 71, 1-8. 
Judit Nagy is a full time adjunct professor at the Department of English Linguistics of the Budapest-based Károli Gáspár University of the Hungarian Reformed Church, where she has been teaching courses in applied linguistics and Canadian Studies. She defended her PhD dissertation entitled But a few Acres of Snow? - Weather Images in Canadian Short Prose (1945-2000) at Eötvös Loránd University in early 2009. Her current fields of research include metaphors in an interdisciplinary approach as well as curriculum and teaching material development in applied linguistics and in Canadian Studies.

Address: Dr. Judit Nagy, PhD., Institute of British and American Studies, Faculty of Humanities, Károli Gáspár University of the Hungarian Reformed Church, 1088 Budapest, Reviczky u. 4, Hungary. [e-mail: nagy.judit@kre.hu] 
